Vol II. No. 1, September 2017, hlm. 55 - 60

Available online at www.jurnal.una.ac.id/indeks/jmp

\title{
PENGARUH MODEL PEMBELAJARAN NUMBERED HEAD TOGETHER (NHT) TERHADAP HASIL BELAJAR MATEMATIKA SISWA DI SMK - SPP NEGERI ASAHAN
}

\author{
Cahayati $^{1}$, Irwan ${ }^{2}$ \\ SMK - SPP Negeri Asahan \\ Email: Chayati93@gmail.com
}

\begin{abstract}
The purpose of this research in Quasy Experimental design is to know the difference of students' mathematics learning result with the Numbered Head Together (NHT) learning model. Population in this research is all student of class X SMK SPP Country of Asahan Year Lesson 2015/2016. The samples in this study were all students of class X BUN B conducted research with the model of learning Numbered Head Together (NHT) and X BUN A conducted research with conventional learning model.From the tests obtained obtained the average value of postes in the experimental class with the model of learning Numbered Head Together (NHT) was 85.94 with standard deviation of 11.03. While in the control class using conventional learning model is 67.19 with standard deviation of 10.54. From the hypothesis test conducted by using two-party test found that H_0 rejected and $\mathrm{H} \_\mathrm{a}$ accepted. Thus it can be concluded that there is an influence between the results of learning mathematics students are taught with the model of learning Numbered Head Together (NHT) Against Students' Mathematics Learning Results on the Materials Logic Class X SMK-SPP Affairs Asahan Year Teaching Year 2015/2016.
\end{abstract}

Keywords: $\quad$ Learning Model Numbered Head Together (NHT), Learning

Outcomes, Mathematical Logic

\begin{abstract}
Abstrak
Tujuan penelitian dalam desain Quasy Eksperimen ini mengetahui perbedaan hasil belajar matematika siswa dengan model pembelajaran Numbered Head Together (NHT). Populasi dalam penelitian ini adalah seluruh siswa kelas X SMK SPP Negeri Asahan Tahun Pelajaran 2015/2016. Sampel pada penelitian ini adalah seluruh siswa kelas X BUN B dilakukan penelitian dengan model pembelajaran Numbered Head Together (NHT) dan X BUN A dilakukan penelitian dengan model pembelajaran konvensional.Dari pengujian yang dilakukan diperoleh nilai rata - rata postes pada kelas eksperimen dengan model pembelajaran Numbered Head Together (NHT) adalah 85,94 dengan simpangan baku 11,03. Sedangkan pada kelas kontrol yang menggunakan model pembelajaran konvensional adalah 67,19 dengan simpangan baku 10,54. Dari uji hipotesis yang dilakukan dengan menggunakan uji dua pihak didapat bahwa $H_{0}$ ditolak dan $H_{a}$ diterima. Dengan demikian dapat disimpulkan bahwa terdapat pengaruh antara hasil belajar matematika siswa yang diajarkan dengan model pembelajaran Numbered Head Together (NHT) Terhadap Hasil Belajar Matematika Siswa pada Materi Logika Kelas X SMK-SPP Negeri Asahan Tahun Ajaran 2015/2016.
\end{abstract}

Kata kunci : Model Pembelajaran Numbered Head Together (NHT),Hasil belajar, Logika matematika 
Vol II. No. 1, September 2017, hlm. 55 - 60

Available online at www.jurnal.una.ac.id/indeks/jmp

Matematika merupakan cabang mata pelajaran yang luas cakupannya dan bukan hanya sekedar bisa berhitung atau menggunakan rumus saja tetapi mencakup beberapa kompetensi yang menjadikan siswa tersebut dapat memahami dan mengerti tentang konsep dasar matematika. Matematika menjadi salah satu pelajaran terpenting yang harus dikuasai oleh setiap orang yang ingin meraih kesuksesan dalam kehidupannya dan banyak sekali manfaat dari aplikasi matematika dalam kehidupan sehari-hari baik diterapkan dalam bidang ilmu lain maupun dalam kehidupan seharihari. Matematika juga sebagai media melatih untuk berpikir kritis, inovatif, kreatif, mandiri dan mampu menyelesaikan masalah.

Dalam hal ini seorang guru memiliki peranan yang sangat penting terhadap pembentukan karakter siswa, baik dalam merencanakan, melaksanakan, dan menilai dalam suatu pembelajaran. Mengajar bukan hanya berusaha untuk menyampaikan ilmu pengetahuan saja melainkan juga berusaha agar tujuan pengajaran dapat tercapai secara optimal.

Hasil studi pendahuluan menunjukkan meskipun matematika diajarkan dengan presentase jam pelajaran yang lebih banyak, namun hasil belajar siswa dalam bidang matematika relatif rendah bila dibandingkan dengan mata pelajaran lain. Faktor penyebab utama adalah guru dan siswa, di mana siswa kurang antusias dalam menerima pelajaran matematika, sedangkan guru tidak dapat menciptakan suasana belajar yang menyenangkan, sehingga siswa kurang aktif dalam pelajaran matematika.

Penggunaan metode ceramah dalam pembelajaran matematika masih banyak digunakan oleh guru. Dalam metode ini siswa cenderung pasif karena dalam mempelajari ilmu sebagian besar diperoleh dari guru, siswa tidak diberi kesempatan untuk membangun pengetahuannya sendiri. Hal ini menyebabkan siswa kurang mandiri dalam belajar matematika. Karena keadaan seperti itu yang selalu dihadapi siswa maka mereka kurang percaya diri dalam menyampaikan pendapat mereka. Maka dari itu guru haruslah berlatih dan memulai untuk kreatifitas dalam mengajar dengan model pembelajaran yang sesuai dengan pokok pelajarannya. Ini dimaksudkan agar siswa kreatif, percaya diri dalam menyampaikan pendapatnya. Oleh karena itu perlu di kembangkan dan diterapkan suatu pembelajaran matematika yang tidak hanya mentransfer pengetahuan guru kepada siswa tetapi pembelajaran matematika hendaknya juga mengaitkan pengalaman kehidupan nyata siswa dengan materi dan konsep matematika. Dengan model-model pembelajaran itu pula terjadi interaksi antar siswa sehingga siswa yang memiliki kemampuan rendah juga memiliki rasa percaya diri dan dapat menambah semangatnya untuk belajar.

Dari uraian permasalahan diatas maka diperlukan model pembelajaran yang diharapkan mampu meningkatkan kemampuan penguasaan matematika dan hasil belajar siswa yaitu dengan menerapkan model pembelajaran kooperatif. Menurut Johnson \& Johnson (Trianto, 2011:57) tujuan pokok belajar kooperatif adalah memaksimalkan belajar siswa untuk 
Vol II. No. 1, September 2017, hlm. 55 - 60

Available online at www.jurnal.una.ac.id/indeks/jmp

peningkatan prestasi akademik dan pemahaman baik secara individu maupun secara kelompok.

Pembelajaran

kooperatif

merupakan strategi pengajaran yang melibatkan siswa bekerja secara berkolaborasi untuk mencapai tujuan bersama. Pembelajaran kooperatif disusun dalam sebuah usaha meningkatkan partisipasi siswa, dengan pengalaman sikap kepemimpinan dan membuat keputusan dalam kelompok, serta memberikan kesempatan pada siswa untuk berinteraksi dan bekerja bersama-sama.

Penerapan model Numbered Head Together (NHT) dalam pembelajaran matematika, khususnya pada materi Logika dapat membuat siswa berperan aktif dalam proses pembelajaran. Model pembelajaran kooperatif tipe $N H T$ merupakan salah satu model yang mudah diterapkan, yang melibatkan aktivitas seluruh siswa tanpa harus membedakan status dan mengandung permainan.

Numbered Head Together (NHT) merupakan salah satu jenis pembelajaran kooperatif yang dirancang untuk mempengaruhi pola interaksi siswa dan alternatif terhadap struktur kelas tradisional dan melibat kan banyak siswa dalam menelaah materi yang tercakup dalam suatu pelajaran Maka dari itu, model pembelajaran Numbered Head Together (NHT) dapat diterapkan dalam proses pembelajaran pada pokok bahasan apapun.

\section{METODE}

Penelitian ini dilaksanakan di SMK-SPP Negeri Asahan. Waktu penelitian dilaksanakan pada semester genap di kelas $X$ tahun ajaran 2015/2016. Populasi pada penelitian ini adalah seluruh siswa kelas X SMK SPP Negeri Asahan yang terdiri dari 5 kelas dengan jumlah keseluruhan sebanyak 148 siswa. Sampel pada penelitan ini adalah kelas X-BUN B dan X-BUN $\mathrm{C}$ yang terpilih secara acak yang berjumlah 64 siswa. Setiap kelas terdiri dari 32 siswa, masingmasing dijadikan sebagai kelas eksperimen dan kelas kontrol. Kelas $\mathrm{X}_{\mathrm{B}}$ sebagai kelas eksperimen dan $\mathrm{X}_{\mathrm{C}}$ sebagai kelas kontrol. Selanjutnya memberikan pretest terhadap kelas eksperimen dan kelas kontrol untuk mengetahui kemampuan awal siswa dan untuk mengetahui apakah kedua kelas tersebut homogen. Mengadakan pembelajaran dengan menggunakan model pembelajaran $N H T$ di kelas eksperimen, dan menggunakan pembelajaran konvensional di kelas kontrol pada materi logika. Setelah pembelajaran di berikan terhadap kedua kelas tersebut, lalu memberikan postest untuk mengetahui kembali hasil belajar matematika setelah dillakukan pembelajaran.

Setelah data penelitian diperoleh dari kedua kelas yang diteliti, kemudian dianalis sehingga digunakan dalam uji hipotesis. Jenis penelitian ini adalah penelitian Quasi Eksperimen Dalam penelitian ini, instrumen yang digunakan berupa tes. Tes yang digunakan adalah tes pilihan berganda. 
Vol II. No. 1, September 2017, hlm. 55 - 60

Available online at www.jurnal.una.ac.id/indeks/jmp

\section{Tabel 1. Perlakuan kelompok}

eksperimen dan kontrol

\begin{tabular}{cccc}
\hline $\begin{array}{c}\text { Kelomp } \\
\text { ok }\end{array}$ & $\begin{array}{c}\text { Prete } \\
\text { st }\end{array}$ & $\begin{array}{c}\text { Perlak } \\
\text { uan }\end{array}$ & $\begin{array}{c}\text { Poste } \\
\text { st }\end{array}$ \\
\hline $\begin{array}{c}\text { Eksperi } \\
\text { men }\end{array}$ & $\mathrm{T}_{1}$ & $\mathrm{X}_{\mathrm{B}}$ & $\mathrm{T}_{2}$ \\
& & &
\end{tabular}

$\mathrm{T}_{1} \quad \mathrm{X}_{\mathrm{C}} \quad \mathrm{T}_{2}$

Kontrol

$\begin{array}{llr}\text { Keterangan : } & \\ \mathrm{T}_{1} & \text { : Tes pendahuluan (Pretest) } \\ \mathrm{T}_{2} & \text { : Tes Akhir (Postest) } \\ \mathrm{X}_{\mathrm{B}} & \text { :Perlakuan } & \text { dengan } \\ & \begin{array}{l}\text { menggunakan } \\ \text { pembelajaran } N H T\end{array} & \text { pendekatan } \\ & \text { :Perlakuan } & \text { dengan } \\ \mathrm{X}_{\mathrm{C}} & \text { menggunakan } & \text { pembelajaran } \\ & \text { Konvensional } & \text { model } \\ & \text { pembelajaran } & \text { kooperatif tipe } \\ & \text { TAI } & \\ \mathrm{X}_{2} & \text { :Perlakuan } & \text { dengan } \\ & \text { menggunakan } & \text { pembelajaran } \\ & \text { Konvensional } & \end{array}$

\section{HASIL DAN PEMBAHASAN}

Sampel penelitian terdiri dari dua kelompok yaitu kelompok eksperimen kelas $\mathrm{X}$ BUN B dengan jumlah siswa 32 orang dan kelompok kontrol kelas X BUN C dengan jumlah siswa 32 orang. Untuk kelompok eksperimen menggunakan model pembelajaran Numbered Head Together (NHT) sedangkan untuk kelompok kontrol menggunakan metode konvensional. Skor yang diberikan memiliki rentang 0-5. Dari hasil pengolahan data pretest untuk masing-masing kelas, yaitu kelas eksperimen dan kelas kontrol, diperoleh nilai maksimum, nilai minimum, nilai rata-rata, dan simpangan baku menunjukkan bahwa harga $\mathrm{L}_{\text {hitung kelas yang diajar tanpa }}$ menggunakan penerapan model Numbered Head Together (NHT) adalah 0,146 dari daftar nilai kritis $\mathrm{L}$ untuk liliefor dengan $\mathrm{N}=32$ dan $\alpha=$ 5\% Diperoleh bahwa harga $\mathrm{L}_{\text {tabel }}=$ 0,157 Harga L Litung dikonsultasikan dengan $\mathrm{L}_{\text {tabel }}$ diperoleh bahwa $\mathrm{L}_{\text {hitung }}<$ $\mathrm{L}_{\text {tanel }}$ yaitu $0,146<0,157$ Sehingga dapat disimpulkan bahwa sebaran data post test siswa kelas kontrol adalah berdistribusi normal.

Untuk dapat melakukan pengujian kesamaan atau perbedaan dua rata-rata. Perlu adanya asumsi bahwa kedua kelompok sampel mempunyai varians yang sama. Pengujian homogenitas data dilakukan dengan menggunakan uji $\mathrm{F}$ pada data post test kedua kelompok sampel. Hasil perhitungan varians post test kedua kelompok sampel, diperoleh :

Varians terbesar (kelas eksperimen) $=$ 106,04

Varians terkecil $($ kelas kontrol $)=127,4$

Dengan menggunakan rumus uji $\mathrm{F}$ yaitu $\mathrm{F}=\frac{\text { Varians Terbesar }}{\text { Varians Terkecil }}$

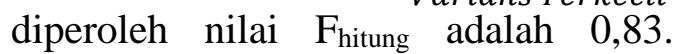
untuk mengetahui homogeny atau tidak homogenya data, maka terlebih dahulu nilai $F_{\text {hitung }}$ dibandingkan dengan nilai $F_{\text {tabel. }}$ Apabila $F_{\text {hitung }}<F_{\text {tabel }}$ maka data homogen. Nilai $F_{\text {tabel }}$ pada taraf $\alpha=$ 0,05 dan $\mathrm{dk}_{\text {pembilang }}=32-1=31$ dan $\mathrm{dk}_{\text {penyebut }}=32-1=31$ adalah 1.84 dengan membandingkan kedua harga terebut diperoleh harga $F_{\text {hitung }}<\mathrm{F}_{\text {tabel }}$ yaitu $0,83<1,84$. Hal ini berarti bahwa varians data pot test kedua kelompok sampel berasal dari populasi yang homogen. 


\section{MATEMATICS PAEDAGOGIC}

Vol II. No. 1, September 2017, hlm. 55 - 60

Available online at www.jurnal.una.ac.id/indeks/jmp

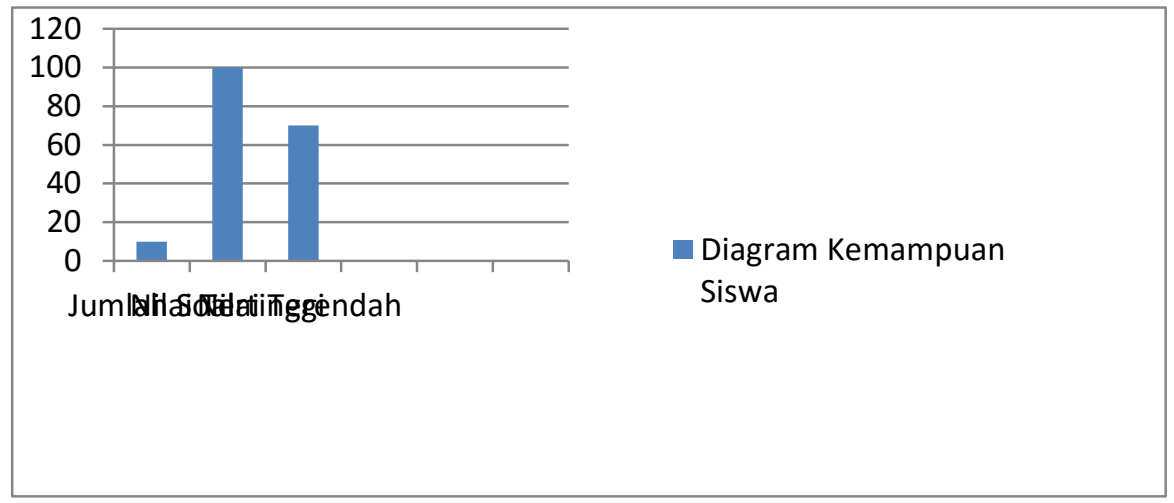

\section{Gambar 1. Ringkasan Hasil Perhitungan Pretest Kelas Eksperimen}

Berdasarkan tabel 4.2 terlihat bahwa nilai terendah yang diperoleh siswa untuk post test adalah 70 dan yang tertinggi adalah 100. Rata-rata nilai post test yang diperoleh kelas dengan perlakuan pembelajaran menggunakan model Numbered Head Together (NHT) adalah 85,94. Standar deviasi adalah 11,03. Rata-rata nilai
85,94 menunjukkan bahwa siswa yang diajar dengan menggunakan model Numbered Head Together (NHT) memiliki tingkat penguasaan materi Menentukan kesimpulan dari beberapa premis yang diberikan dengan prinsip modus ponens, modus tolens, dan silogisme.

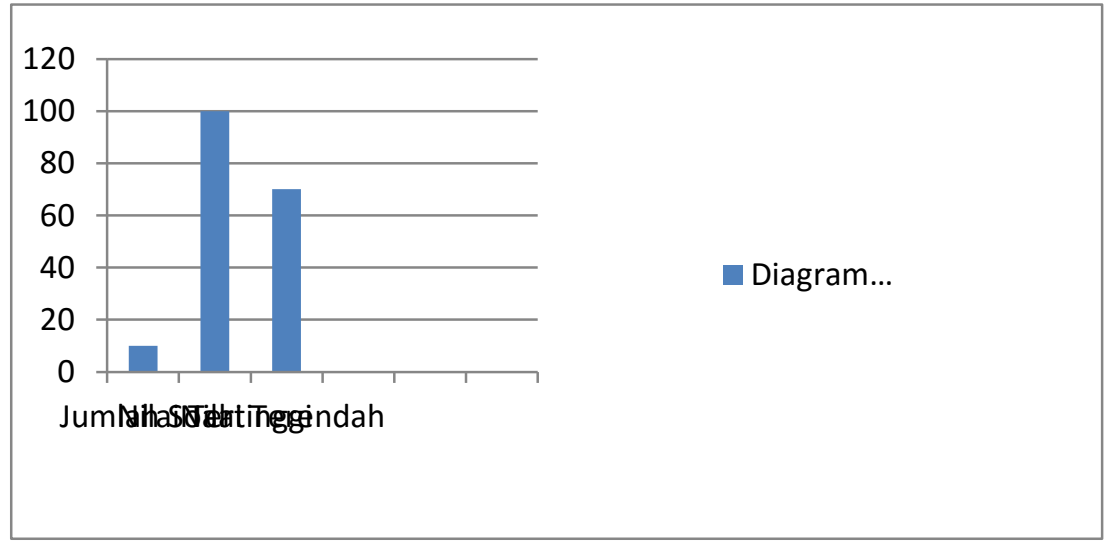

\section{Gambar 2. Ringkasan Hasil Perhitungan Postest Kelas Kontrol}

Berdasarkan gambar 2 terlihat bahwa nilai terendah yang diperoleh siswa untuk post test adalah 70 dan yang tertinggi adalah 100. Rata-rata nilai post test yang diperoleh kelas tanpa perlakuan pembelajaran menggunakan model Numbered Head Together (NHT) adalah 67,18, standar deviasi adalah 10,54, dan varians adalah 111,19 . Rata-rata nilai 67,18 menunjukkan bahwa siswa yang diajar dengan metode ekperimen memiliki tingkat penguasaan materi menentukan kesimpulan dari beberapa premis yang diberikan dengan prinsip modus 
Vol II. No. 1, September 2017, hlm. 55 - 60

Available online at www.jurnal.una.ac.id/indeks/jmp

ponens, modus tolens, dan silogisme adalah kurang.

Kelas yang diajar dengan menggunakan model Numbered Head Together (NHT) dengan jumlah siswa $(\mathrm{n})=32$ diperoleh nilai maksimum 100 , nilai minimum $=70$, rata-rata $=$ 85,93, simpangan baku $(S)=10.03$ Dan varians $\left(S^{2}\right)=121,67$ kelas yang diajar tanpa menggunakan model Numbered Head Together (NHT) dengan jumlah siswa $(\mathrm{n})=32$ diperoleh nilai maksimum 100 , nilai minimum 70 , rata-rata $=67,19$ simpangan baku $(\mathrm{S})$ $=10.54$ Dan varians $\left(S^{2}\right)=111,19$

Hasil pengujian hipotesis thitung $=1,78$ pada lampiran 33 dengan menggunakan daftar distribusi $t$ dapat ditemukan bahwa harga $t_{\text {tabel }}$ pada tingkat keyakinan 95\%dengan derajat kebebasan $(\mathrm{dk})(32+32-2=62)$ adalah 1,67 Harga $t_{\text {hitung }}(1,78)>t_{\text {tabel }}(1,67)$, yang berarti bahwa hasil belajar matematika siswa yang diajar dengan menggunakan model pembelajaran Numbered Head Together (NHT) lebih baik dibanding dengan hasil belajar matematika siswa yang diajar dengan metode kovensional.

\section{DAFTAR RUJUKAN}

Arikunto, Suharsimi. (2011). Dasar Dasar Evaluasi Pendidikan ( Edisi Revisi). Jakarta: Bumi Aksara.

Arsyad, Azhar.(2007). Media Pembelajaran. Jakarta: PT. RajaGrafindo

Istarani. (2011). 58 Model Pembelajaran Inovatif, Medan: Media Persada.

Sanjaya, Wina. 2007. Strategi Pembelajaran Berorientasi

\section{SIMPULAN}

Berdasarkan pengolahan data dan hasil analisis serta pembahasan, maka dapat diperoleh kesimpulan bahwa perbandingan hasil belajar matematika kelas eksperimen lebih baik dibandingkan dengan hasil belajar kelas control.

\section{saran}

Penelitian pengaruh pembelajaran dengan menggunakan model Numbered Head Together (NHT) dapat meningkatkan hasil belajar matematika siswa. Bagi guru model pembelajaran ini dapat meningkatkan dan memperbaiki system pembelajaran di kelas, bagi sekolah model-model pembelajaran sebagai referensi untuk menarik perhatian para guru agar meningkatkan kretifitas dan inovasi dalam pembelajaran, serta bagi peneliti model pembelajaran ini sebagai bahan informasi dan masukan yang bermanfaat sekaligus sebagai bahan pegangan peneliti dalam menjalankan tugas pengajaran sebagai calon pengajar di masa yang akan datang.

\section{Standar Proses Pendidikan. Jakarta: Kencana Prenada Media.}

Sudjana. (2005). Metoda Statistika. Bandung: Tarsito.

Trianto. (2009). Mendesain Model Pembelajaran InovatifProgresif: Konsep, Landasan, dan Implementasinya pada Kurikulum Tingkat Satuan Pendidikan (KTSP). Surabaya : Kencana Prenada Media Group. 
Vol II. No. 1, September 2017, hlm. 55 - 60

Available online at www.jurnal.una.ac.id/indeks/jmp 